\title{
PENGEMBANGAN KOMPETENSI LANJUTAN PROGRAM STUDI DIPLOMA IV TRANSPORTASI DARAT KE JENJANG MAGISTER TERAPAN
}

\author{
DR. Gloria Novita, MT \\ Dosen STTD \\ J1. Raya Setu No. 89, Bekasi \\ Telp./Fax : (021) 8254640 \\ Dessy Angga A, M.SC \\ Dosen STTD \\ J1. Raya Setu No. 89, Bekasi \\ Telp./Fax : (021) 8254640
}

\author{
Asrizal, ATD, MT \\ Dosen STTD \\ J1. Raya Setu No. 89, Bekasi \\ Telp./Fax : (021) 8254640
}

Sabrina Handayani, MT

Dosen STTD

Jl. Raya Setu No. 89, Bekasi

Telp./Fax : (021) 8254640

\begin{abstract}
STTD as an official higher education institution under the BPSDM Ministry of Transportation has a mandate to manage study programs according to their main tasks and functions in meeting HR needs. In an effort to produce professional human resources to handle service needs and the development of land transportation systems both at national and global levels, STTD has put in place a strategic plan for 2015-2023 education development in the framework of the comprehensive understanding of land transportation knowledge and technology. In line with that, the Applied Transport Master Program is in the Master Plan for the Development of STTD and at the same time is in line with the STTD Land Transportation Polytechnic Academic Manuscript which is currently in progress. With the Polytechnic institutional form, namely vocational education, the appropriate form is an applied master. The opportunity is quite large considering that currently there is no Applied Transport Master in Indonesia.
\end{abstract}

Keywords: Educational Institutions, Competency Development, applied masters

\begin{abstract}
ABSTRAKSI
STTD sebagai sebuah lembaga pendidikan tinggi kedinasan di bawah BPSDM Kementerian Perhubungan mempunyai mandat untuk mengelola program studi sesuai tugas pokok dan fungsi dalam memenuhi kebutuhan SDM. Dalam upaya menghasilkan
\end{abstract}


SDM professional untuk menangani kebutuhan layanan dan pengembangan sistem transportasi darat baik pada tataran nasional maupun global, STTD telah meletakkan rencana strategis pengembangan pendidikan 2015-2023, dalam kerangka pengeuasan pengetahuan dan teknologi transportasi darat yang utuh. Sejalan dengan itu, Program Magister Terapan Transportasi ada di dalam Rencana Induk Pengembangan STTD dan sekaligus juga sejalan dengan Naskah Akademik Politeknik Sekolah Tinggi Transportasi Darat STTD yang sedang berproses. Dengan bentuk kelembagaan Politeknik, yaitu pendidikan vokasi ini, maka bentuk yang sesuai adalah magister terapan. Peluang yang dimiliki cukup besar mengingat saat ini di Indonesia belum terdapat Magister Terapan Transportasi.

Kata Kunci : Lembaga Pendidikan, Pengembangan Kompetensi, magister terapan

\section{PENDAHULUAN}

Dalam upaya menghasilkan SDM professional untuk menangani kebutuhan layanan dan pengembangan sistem transportasi darat baik pada tataran nasional maupun global, STTD telah meletakkan rencana strategis pengembangan pendidikan 2015-2023 dalam kerangka pengeuasan pengetahuan dan teknologi transportasi darat yang utuh. Terapan Transportasi adalah penerapan prinsipprinsip saintifik dan teknologi untuk merencanakan, merancang fungsi dan operasi serta fasilitas untuk setiap moda transportasi agar dapat menyediakan pergerakan manusia dan barang secara aman, efisien, cepat, nyaman, dan ekonomis. Keilmuan dari Transportasi bersumber dari berbagai disiplin ilmu yang menjadi pendekatan yaitu Perencanaan Transportasi (Public Transport), Rekayasa Lalu Lintas (Traffic Engineering), Angkutan Umum (Public Transport), Keselamatan Transportasi (Transport Safety), Rekayasa Kendaraan (Vehicle Engineering), Hukum Transport (Transport Law), Ekonomi Transport (Transport Economic), Administrasi Publik (Public Administration), Transport Multi Moda dan Inter Moda (Multi Mode and Inter Mode Transportation), Kuantifikasi dan Komputasi Transportasi (Quantification and Computation Transport). Berdasarkan posisi 
pengembangan ilmu dan teknologi di bidang transportasi tersebut, maka Rencana Strategis STTD 2015-2023 akan mencakup pengembangan di bidang sistem transportasi. Sejalan dengan itu, Program Magister Terapan Transportasi ada di dalam Rencana Induk Pengembangan STTD dan sekaligus juga sejalan dengan Naskah Akademik Politeknik Sekolah Tinggi Transportasi Darat STTD yang sedang berproses. Dengan bentuk kelembagaan Politeknik, yaitu pendidikan vokasi ini, maka bentuk yang sesuai adalah magister terapan. Peluang yang dimiliki cukup besar mengingat saat ini di Indonesia belum terdapat Magister Terapan Transportasi.

\section{TuJuAn PENELITIAN}

Tujuan dilaksnakannya penelitian ini meliputi:

1. Menganalisis Profil Lulusan D. IV Transportasi Darat saat ini dan kebutuhan profil dengan kompetensi lanjutan

2. Menyusun Pemetaan Capaian Pembelajaran sesuai Profil Lulusan Magister Terapan Transportasi

3. Menyusun Kurikulum dan Silabi Magister Terapan Transportasi

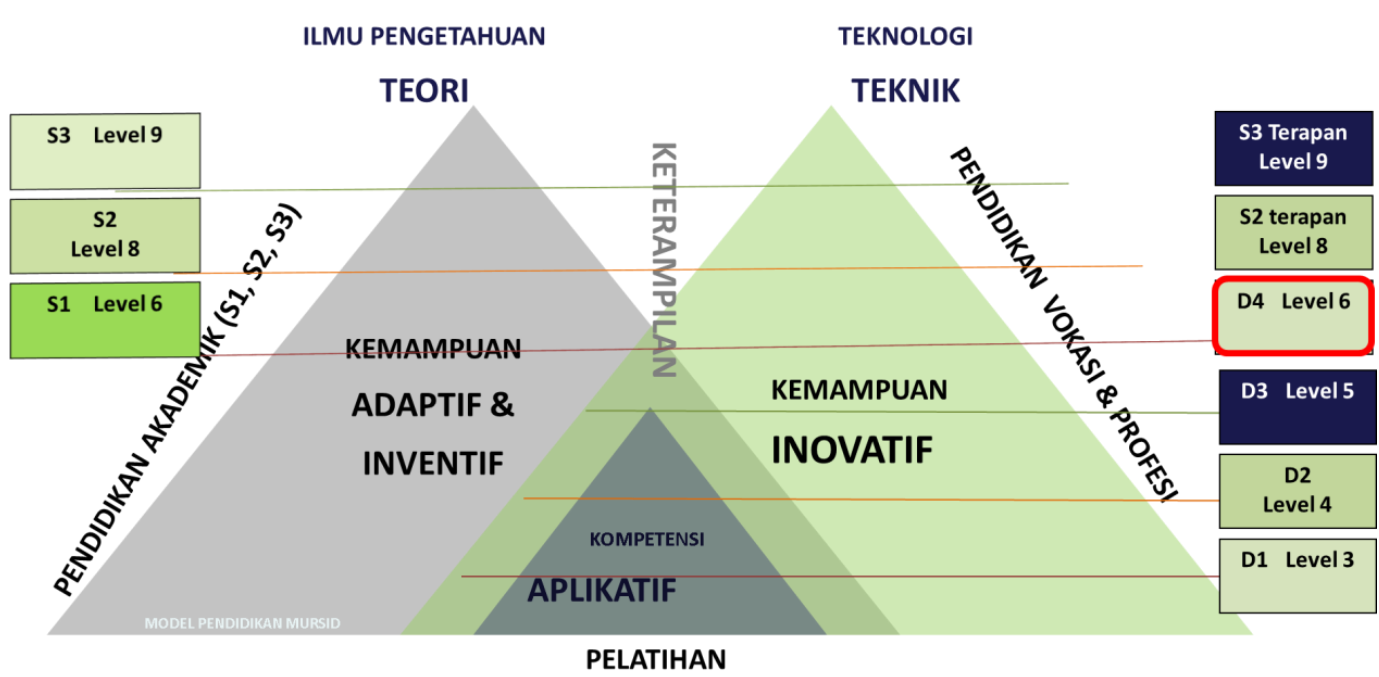

Kaitan antara pendidikan Akademik dan Pendidikan Vokasi/Profesi 


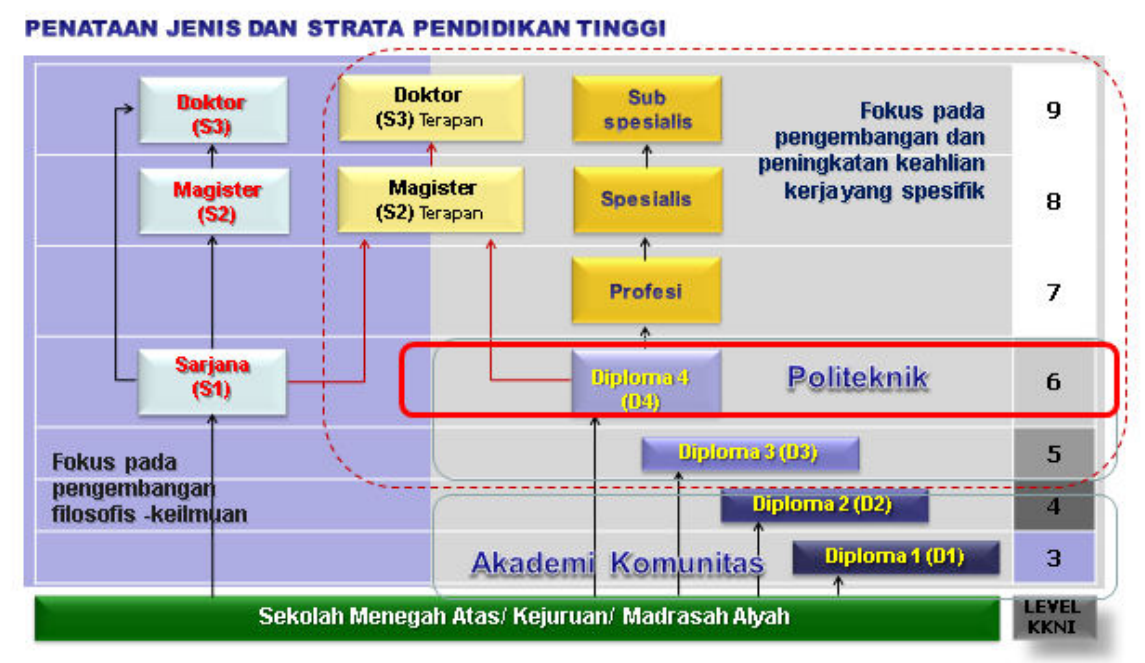

Kaitan antara pendidikan Akademik dan Pendidikan Vokasi/Profesi

\section{Metodologi Penelitian}

\section{POLA PIKIR PENELITIAN}

Saat ini telah STTD telah menyelenggarakan program studi D. IV Transportasi Darat dan berdasarkan kebutuhan kompetensi kerja, diperlukan program studi lanjutan untuk mengembangkan kompetensi lulusan dari D. IV Transportasi Darat. Saat ini sebagian dari lulusan D. IV Transportasi Darat telah melanjutkan studi di magister, tetapi magister yang mengikuti alur pendidikan akademik, dan bukan pendidikan vokasi. Untuk kelanjutan studi D IV Transportasi Darat yang merupakan pendidikan vokasi, yang komposisi praktek lebih dominan disbanding teori, maka dipandang bahwa studi lanjutan yang paling tepat untuk Diploma IV Transportasi Darat adalah Magister Terapan. Untuk itu perlu tahapan penelitian sebagai benih dari pembentukan program studi Magister Transportasi.

\section{Metode Pengumpulan Data}

Pada penelitian ini dibutuhkan data primer dan sekunder sebagai berikut:

\section{Data Primer:}

1. Data Pelacakan Lulusan/ Tracer Study berupa kompetensi real di bidang tugas yang dialami dan dirasakan oleh lulusan D. IV Transportasi Darat 
2. Data Umpan Balik Alumni dan Stakeholder Pengguna lulusan melalui Wawancara

Data Sekunder :

1. Peraturan dan Perundang-undangan terkait Pendidikan Tinggi, BNSP dan SKKNI

2. Data Hasil Inventarisasi Kurikulum dan Capaiakan Pembelajaran dan kurikulum program studi pembanding yang relevan (terapan dan transportasi)

3. Peraturan dan Kebijakan yang relevan dengan STTD, BPSDM, Kementerian Perhubungan

4. Literatur dan penelitian yang relevan

\section{MEtOdE ANALISIS}

Analisa Data pada penelitian dilakukan dengan

1. Studi Literatur terhadap

2. Analisa Hasil Tracer Study dan Wawancara Pengguna Lulusan

3. Kompilasi Data Prodi relevan pembanding dan Posisioning

4. Analisa Penyusunan Kurikulum

Luaran yang dihasilkan dari penelitiuan berupa

1. Rumusan Profil Lulusan Magister Terapan Transportasi STTD;

2. Capaian Pembelajaran Magister Terapan Transportasi STTD;

3. Kurikulum Magister Terapan Transportasi

4. Deskripsi Pembelajaran Magister Terapan Transportasi

\section{PERUMUSAN PROFIL LULUSAN}

Berdasarkan hasil analisis kondisi eksisting lulusan Program Studi D.IV Transportasi darat yang menghasilkan data tentang kebutuhan kompetensi lanjutan bagi para lulusan, dan analisis posisi Program Studi S2 Transportasi memiliki fokus yang berbeda dengan Program Studi S2 Transportasi serumpun ilmu di 7 universitas tersebut di atas. Maka penyusunan Program Studi S2 Transportasi di STTD memiliki kemampuan lulusan (Profil Lulusan) antara lain: 
1. Ahli Pemodelan Transportasi

2. Ahli Rekayasa Lalu Lintas

3. Ahli Integrasi Inter dan Antar Moda

4. Ahli Sistem Operasional Angkutan Umum

\section{PERUMusan CAPAiAn PEMBELAJARAN}

Berdasarkan profil lulusan, maka dirumusakan Capaian pembelajaran dengan descriptor Capaian Pembelajaran Program Studi S2 Transportasi sebagaimana ditunjukkan pada Tabel IV. 5 berikut ini

Deskriptor Capaian Pembelajaran Magister Terapan

\begin{tabular}{|c|c|c|}
\hline \multicolumn{3}{|c|}{ I. $\quad$ Keterangan Umum } \\
\hline 1. & Perguruan Tinggi & Sekolah Tinggi Transportasi Darat \\
\hline 2. & Fakultas/Sekolah/Jurusan & Transportasi \\
\hline 3. & Nama Program Studi/Jenjang & S2 Transportasi \\
\hline 4. & Bidang Keilmuan & Transportasi \\
\hline \multirow[t]{2}{*}{5.} & \multirow[t]{2}{*}{ Penyusun Deskriptor } & - \\
\hline & & Calon Ketua Program Studi \\
\hline \multicolumn{3}{|c|}{ Kualifikasi Hasil Pendidikan Program Studi } \\
\hline 6. & $\begin{array}{ll}\text { Yang } \quad \text { Berwenang } & \text { Dalam } \\
\text { Menetapkan Kualifikasi } & \end{array}$ & $\begin{array}{l}\text { Menteri Riest Teknologi dan Pendidikan Tinggo } \\
\text { dan Menteri Perhubungan Republik Indonesia }\end{array}$ \\
\hline 7. & Mekanisme Penetapan Kualifikasi & $\begin{array}{l}\text { Senat yang dipimpin oleh Ketua Sekolah Tinggi } \\
\text { Transportasi Darat membentuk tim untuk } \\
\text { menyusun draf penetapan kualifikasi. Draf } \\
\text { penetapan kualifikasi diajukan ke rapat senat untuk } \\
\text { dibahas dan disahkan oleh senat yang dipimpin } \\
\text { oleh Ketua Sekolah Tinggi Transportasi Darat. }\end{array}$ \\
\hline 8 & \multicolumn{2}{|c|}{$\begin{array}{l}\text { Capaian Pembelajaran Dan Kompetensi } \\
\text { Program Studi S2 Transportasi Sekolah Tinggi Transportasi Darat menetapkan standar } \\
\text { kualifikasi Hasil Pendidikan (Learning Outcomes) yang mencakup berikut: } \\
\text { 1. Setiap lulusan memiliki sikap sebagai berikut: } \\
\text { a. bertakwa kepada Tuhan Yang Maha Esa dan mampu menunjukkan sikap } \\
\quad \text { religius; } \\
\text { b. menjunjung tinggi nilai kemanusiaan dalam menjalankan tugas berdasarkan }\end{array}$} \\
\hline
\end{tabular}




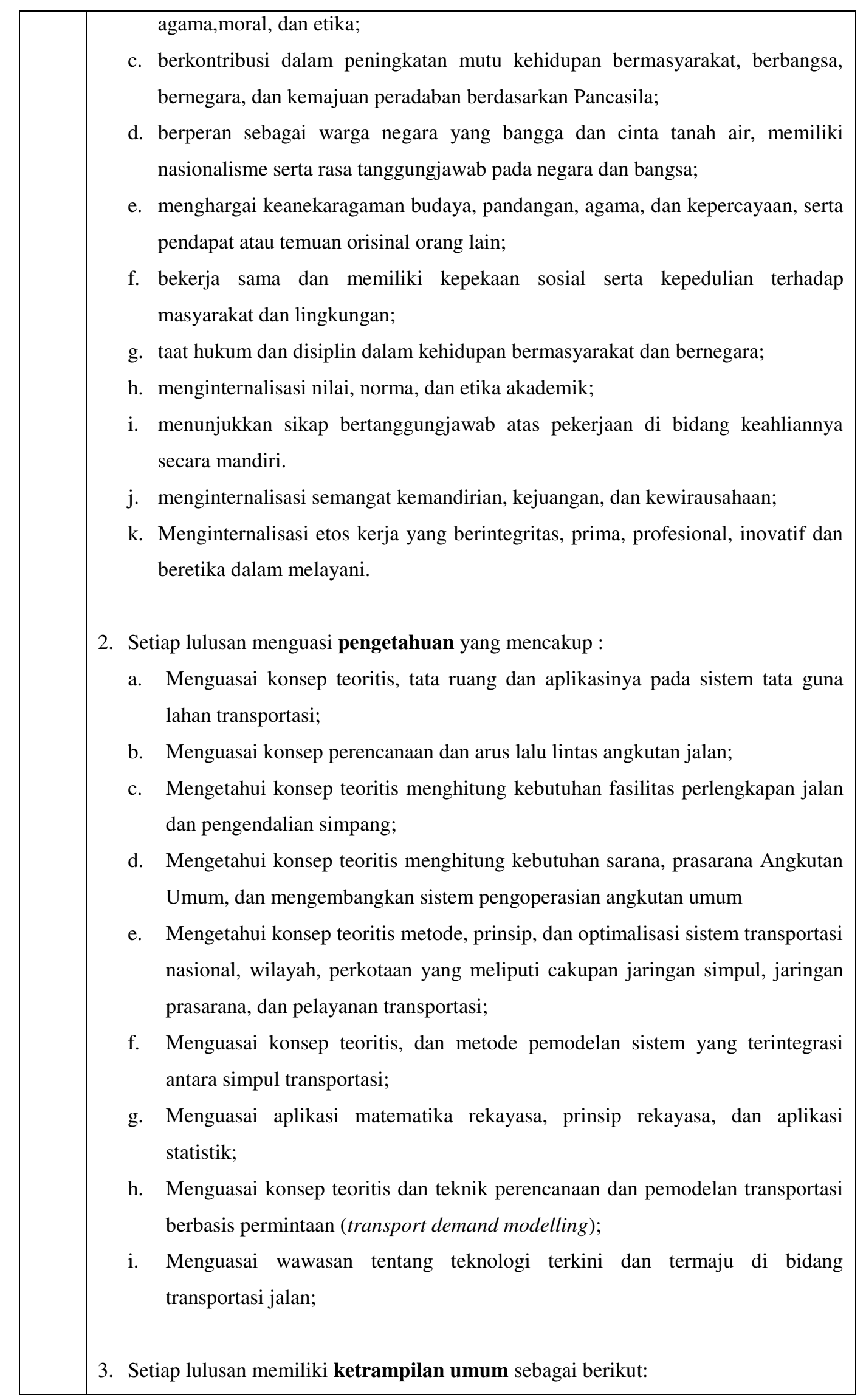


a. mampu menerapkan pemikiran logis, kritis, inovatif, bermutu, dan terukur dalam melakukan pekerjaan yang spesifik di bidang keahliannya serta sesuai dengan standar kompetensi kerja bidang yang bersangkutan;

b. mampu menyelesaikan pekerjaan berlingkup luas dan menganalisis data dengan beragam metode sesuai, baik yang belum maupun yang sudah baku;

c. mampu menyusun laporan hasil dan proses belajar secara akurat dan mengkomunikasikannya secara efektif kepada pihak lain yang membutuhkan;

d. mampu bekerja sama, berkomunikasi dan berinovasi dalam pekerjaannya;

e. mampu bertanggung jawab atas pencapaian hasil kerja kelompok dan melakukan supervisi dan evaluasi terhadap penyelesaian pekerjaan yang ditugaskan kepada pekerja yang berada dibawah tanggung jawabnya

f. mampu melakukan proses evaluasi diri terhadap kelompok kerja yang berada dibawah tanggung jawabnya, dan mampu mengelola pembelajaran secara mandiri;

g. mampu mendokumentasikan, menyimpan, mengamankan, dan menemukan kembali data untukmenjamin kesahihan dan mencegah plagiasi

h. mampu beradaptasi, bekerja sama, berkreasi dan berkontribusi dan berinovasi dalam menerapkan ilmu pengetahuan pada kehidupan bermasyarakat serta mampu berperan sebagai warga dunia yang berwawasan global;

i. mampu meneggakkan integritas akademik secara umum dan mencegah terjadinya praktik plagiarisme;

j. mampu menggunakan teknologi informasi dalam konteks pengembangan keilmuan dan implementasi bidang keahlian;

k. mampu menggunakan minimal satu bahasa internasional untuk komunikasi lisan dan tulis;

4. Setiap lulusan memiliki ketrampilan khusus sebagai berikut:

a. Mampu merancang dan membangun model sistem transportasi perkotaan, wilayah dan nasional;

b. Mampu mengevaluasi sistem rekayasa lalu lintas dalam lingkup makro dan mikro dan memberikan evaluasi pemecahan masalah terhadap penerapan rekayasa lalu lintas;

c. Mampu merancang rekayasa lalu lintas;

d. Mampu mengimplementasikan dan mengevaluasi kinerja jaringan angkutan umum, kinerja operasional angkutan umum, dan kinerja kepengusahaan angkutan umum serta mengembangkan manajemen angkutan umum;

e. Mampu mengintegrasikan aspek sarana dan prasarana transportasi baik inter maupun antar moda dalam pengoperasian, dan pelayanan; 


\section{Pembentukan Mata Kuliah}

1. Rumpun Keilmuan

Bidang ilmu Program Studi DIV S2 Transportasi Terapan mempunyai bidang ilmu yang berkaitan antara materi pokok Program Studi dengan bidang ilmu seperti dibawah ini:

Rumpun Keilmuan

\begin{tabular}{|l|l|c|c|c|c|c|}
\hline \multicolumn{1}{|c|}{ Bidang ilmu } & $\begin{array}{c}\text { T. Sipil dan } \\
\text { Lingkungan }\end{array}$ & $\begin{array}{c}\text { T. } \\
\text { Elektro }\end{array}$ & $\begin{array}{c}\text { T. } \\
\text { Transport } \\
\text { asi }\end{array}$ & $\begin{array}{c}\text { T. } \\
\text { Mesin }\end{array}$ & $\begin{array}{c}\text { Eko } \\
\text { nomi }\end{array}$ & $\begin{array}{c}\text { Mana } \\
\text { jemen }\end{array}$ \\
\hline Sistem Transportasi & $\sqrt{ }$ & & $\sqrt{ }$ & & & \\
\hline Rekayasa Lalu Lintas dan & $\sqrt{ }$ & & $\sqrt{ }$ & & & \\
\hline $\begin{array}{l}\text { Perencanaan } \\
\text { pemodelan transportasi } \\
\text { berbasis integrasi }\end{array}$ & & & & & & \\
\hline
\end{tabular}

Bahan Kajian yang diturunkan dari Capaian Pembelajaran (CP)

Perumusan bahan kajian memiliki esensi penting untuk mencapai Learning

Outcomes (LO) terutama yang terkait dengan penguasaan kemampuan ketrampilan khusus. Setiap bahan kajian akan dijabarkan lebih lanjut dalam penyusunan mata kuliah yang terkait dengan bahan kajian ini :

Bahan Kajian dari Capaian Pembelajaran

\begin{tabular}{|c|c|c|c|c|c|c|c|c|}
\hline \multicolumn{9}{|c|}{ Capaian Pembelajaran } \\
\hline \multirow[t]{2}{*}{ No } & \multirow[t]{2}{*}{ Bahan Kajian } & \multirow[t]{2}{*}{ Sikap } & \multicolumn{5}{|c|}{ Ketrampilan Khusus } & \multirow{2}{*}{$\begin{array}{l}\text { Ketrampil } \\
\text { an Umum }\end{array}$} \\
\hline & & & $\mathrm{A}$ & B & $\mathrm{C}$ & $\mathrm{D}$ & $\mathrm{E}$ & \\
\hline 1 & $\begin{array}{l}\text { Konsep teoritis, tata ruang dan } \\
\text { aplikasinya pada sistem tata guna lahan } \\
\text { transportasi }\end{array}$ & $\square$ & $\square$ & $\square$ & $\square$ & $\square$ & $\square$ & $\square$ \\
\hline 2 & $\begin{array}{l}\text { Konsep perencanaan dan arus lalu lintas } \\
\text { angkutan jalan }\end{array}$ & $\square$ & $\square$ & $\square$ & $\square$ & & $\square$ & $\square$ \\
\hline 3 & $\begin{array}{l}\text { Konsep teoritis menghitung kebutuhan } \\
\text { fasilitas perlengkapan jalan dan } \\
\text { pengendalian simpang }\end{array}$ & $\square$ & $\square$ & $\square$ & $\square$ & & $\square$ & $\square$ \\
\hline
\end{tabular}




\begin{tabular}{|c|c|c|c|c|c|c|c|c|}
\hline 4 & $\begin{array}{l}\text { Konsep teoritis menghitung kebutuhan } \\
\text { sarana, prasarana Angkutan Umum, dan } \\
\text { mengembangkan sistem pengoperasian } \\
\text { angkutan umum }\end{array}$ & $\square$ & $\square$ & $\square$ & $\square$ & $\square$ & $\square$ & $\square$ \\
\hline 5 & $\begin{array}{l}\text { Konsep teoritis metode, prinsip, dan } \\
\text { optimalisasi sistem transportasi } \\
\text { nasional, wilayah, perkotaan yang } \\
\text { meliputi cakupan jaringan simpul, } \\
\text { jaringan prasarana, dan pelayanan } \\
\text { transportasi }\end{array}$ & $\square$ & $\square$ & $\square$ & & & $\square$ & $\square$ \\
\hline 6 & $\begin{array}{l}\text { Konsep teoritis, dan metode pemodelan } \\
\text { sistem yang terintegrasi antara simpul } \\
\text { transportasi }\end{array}$ & $\bar{\square}$ & $\begin{array}{ll}\square \\
\end{array}$ & $\square$ & $\begin{array}{ll}\square \\
\end{array}$ & $\bar{\square}$ & $\begin{array}{ll}\square \\
\end{array}$ & $\bar{\square}$ \\
\hline 7 & $\begin{array}{l}\text { Aplikasi matematika rekayasa, prinsip } \\
\text { rekayasa, dan aplikasi statistic }\end{array}$ & $\square$ & $\square$ & $\square$ & $\square$ & & $\square$ & $\square$ \\
\hline 8 & $\begin{array}{l}\text { konsep teoritis dan teknik } \\
\text { perencanaan dan pemodelan } \\
\text { transportasi berbasis permintaan } \\
\text { (transport demand modelling) }\end{array}$ & $\square$ & $\square$ & & & & $\square$ & $\square$ \\
\hline 9 & $\begin{array}{l}\text { Menguasai wawasan tentang } \\
\text { teknologi terkini dan termaju di } \\
\text { bidang transportasi jalan }\end{array}$ & $\square$ & $\square$ & $\square$ & $\square$ & $\square$ & $\square$ & $\square$ \\
\hline
\end{tabular}

a. Bahan kajian dengan kebutuhan mata kuliah:

Kaitan antara Bahan Kajian dari Mata Kuliah

\begin{tabular}{|l|l|l|l|l|l|l|l|l|l|}
\hline \multirow{2}{*}{ MATA KULIAH } & \multicolumn{9}{|l|}{ BAHAN KAJIAN } \\
\cline { 2 - 10 } & 1 & 2 & 3 & 4 & 5 & 6 & 7 & 8 & 9 \\
\hline $\begin{array}{l}\text { Perencanaan dan Pemodelan } \\
\text { Transportasi }\end{array}$ & & & & & & & & & \\
\hline $\begin{array}{l}\text { Perencanaan dan Kebijakan } \\
\text { Transportasi }\end{array}$ & & & & & & & & & \\
\hline Transportasi dan Tata Guna Lahan & & & & & & & & & \\
\hline
\end{tabular}




\begin{tabular}{|l|l|l|l|l|l|l|l|l|l|}
\hline \multirow{2}{*}{ MATA KULIAH } & \multicolumn{6}{|l|}{ BAHAN KAJIAN } \\
\cline { 2 - 10 } & 1 & 2 & 3 & 4 & 5 & 6 & 7 & 8 & 9 \\
\hline Ekonomi Transportasi & & & & & & & & & \\
\hline Sistem Angkutan Umum & & & & & & & & & \\
\hline Lalu Lintas dan Pergerakan & & & & & & & & & \\
\hline Manajemen Prasarana Transportasi & & & & & & & & & \\
\hline Metodologi Penelitian & & & & & & & & & \\
\hline Metode Analisis Transportasi & & & & & & & & & \\
\hline Sistem Transportasi Cerdas (ITS) & & & & & & & & & \\
\hline Manajemen dan Rekayasa Lalu Lintas & & & & & & & & & \\
\hline Infrastruktur \\
Berkelanjutan
\end{tabular}

Mata Kuliah yang mengait pada Bahan Kaiian

\begin{tabular}{|c|c|c|}
\hline No & Bahan Kajian & Mata Kuliah \\
\hline 1 & $\begin{array}{l}\text { Konsep teoritis, tata ruang dan } \\
\text { aplikasinya pada sistem tata guna } \\
\text { lahan transportasi }\end{array}$ & $\begin{array}{l}\text { a. Perencanaan dan Pemodelan Transportasi } \\
\text { b. Perencanaan dan Kebijakan Transportasi } \\
\text { c. Transportasi dan Tata Guna Lahan } \\
\text { d. Sistem Angkutan Umum } \\
\text { e. Lalu Lintas dan Pergerakan } \\
\text { f. Manajemen Prasarana Transportasi } \\
\text { g. Metode Analisis Transportasi } \\
\text { h. Sistem Transportasi Cerdas (ITS) } \\
\text { i. Infrastruktur Transportasi Berkelanjutan } \\
\text { j. Keselamatan Lalu Lintas } \\
\text { k. Sistem Transportasi Terpadu } \\
\text { 1. Rekayasa Sistem Pelayanan Angkutan Barang } \\
\text { m. Kebijakan Publik }\end{array}$ \\
\hline 2 & $\begin{array}{l}\text { Konsep perencanaan dan arus lalu } \\
\text { lintas angkutan jalan }\end{array}$ & $\begin{array}{l}\text { a. Perencanaan dan Pemodelan Transportasi } \\
\text { b. Perencanaan dan Kebijakan Transportasi }\end{array}$ \\
\hline
\end{tabular}




\begin{tabular}{|c|c|c|}
\hline No & Bahan Kajian & Mata Kuliah \\
\hline & & $\begin{array}{l}\text { c. Transportasi dan Tata Guna Lahan } \\
\text { d. Sistem Angkutan Umum } \\
\text { e. Lalu Lintas dan Pergerakan } \\
\text { f. Manajemen Prasarana Transportasi } \\
\text { g. Metode Analisis Transportasi } \\
\text { n. Sistem Transportasi Cerdas (ITS) } \\
\text { o. Manajemen dan Rekayasa Lalu Lintas } \\
\text { p. Keselamatan Lalu Lintas } \\
\text { q. Sistem Transportasi Terpadu } \\
\text { r. Rekayasa Sistem Pelayanan Angkutan Barang }\end{array}$ \\
\hline 3 & $\begin{array}{l}\text { Konsep teoritis } \quad \text { menghitung } \\
\text { kebutuhan fasilitas } \\
\text { jalan dan pengendalian simpang }\end{array}$ & $\begin{array}{l}\text { a. Perencanaan dan Pemodelan Transportasi } \\
\text { b. Transportasi dan Tata Guna Lahan } \\
\text { c. Lalu Lintas dan Pergerakan } \\
\text { d. Manajemen Prasarana Transportasi } \\
\text { e. Sistem Transportasi Cerdas (ITS) } \\
\text { s. Manajemen dan Rekayasa Lalu Lintas } \\
\text { f. Infrastruktur Transportasi Berkelanjutan } \\
\text { g. Keselamatan Lalu Lintas } \\
\text { h. Sistem Transportasi Terpadu } \\
\text { i. Rekayasa Sistem Pelayanan Angkutan Barang } \\
\text { j. Kebijakan Publik }\end{array}$ \\
\hline 4 & $\begin{array}{lrr}\text { Konsep teoritis } & \text { menghitung } \\
\text { kebutuhan sarana, } & \text { prasarana } \\
\text { Angkutan Umum, } & \text { dan } \\
\text { mengembangkan } & \text { sistem } \\
\text { pengoperasian angkutan umum }\end{array}$ & $\begin{array}{l}\text { a. Perencanaan dan Pemodelan Transportasi } \\
\text { b. Perencanaan dan Kebijakan Transportasi } \\
\text { c. Transportasi dan Tata Guna Lahan } \\
\text { d. Ekonomi Transportasi } \\
\text { e. Sistem Angkutan Umum } \\
\text { f. Sistem Transportasi Cerdas (ITS) } \\
\text { g. Infrastruktur Transportasi Berkelanjutan } \\
\text { h. Keselamatan Lalu Lintas } \\
\text { i. Sistem Transportasi Terpadu } \\
\text { j. Kebijakan Publik }\end{array}$ \\
\hline 5 & $\begin{array}{l}\text { Konsep teoritis metode, prinsip, dan } \\
\text { optimalisasi sistem transportasi } \\
\text { nasional, wilayah, perkotaan yang } \\
\text { meliputi cakupan jaringan simpul, } \\
\text { jaringan prasarana, dan pelayanan }\end{array}$ & $\begin{array}{l}\text { a. Perencanaan dan Pemodelan Transportasi } \\
\text { b. Perencanaan dan Kebijakan Transportasi } \\
\text { c. Transportasi dan Tata Guna Lahan } \\
\text { d. Ekonomi Transportasi } \\
\text { e. Sistem Angkutan Umum }\end{array}$ \\
\hline
\end{tabular}




\begin{tabular}{|c|c|c|}
\hline No & Bahan Kajian & Mata Kuliah \\
\hline & transportasi & $\begin{array}{l}\text { f. } \text { Lalu Lintas dan Pergerakan } \\
\text { g. Sistem Transportasi Cerdas (ITS) } \\
\text { h. Sistem Transportasi Terpadu } \\
\text { i. } \quad \text { Rekayasa Sistem Pelayanan Angkutan Barang } \\
\text { j. Kebijakan Publik }\end{array}$ \\
\hline 6 & $\begin{array}{l}\text { Konsep teoritis, dan metode } \\
\text { pemodelan sistem yang terintegrasi } \\
\text { antara simpul transportasi }\end{array}$ & $\begin{array}{l}\text { a. Perencanaan dan Pemodelan Trasportasi } \\
\text { b. Perencanaan dan Kebijakan Transportasi } \\
\text { c. Transportasi dan Tata Guna Lahan } \\
\text { d. Sistem Angkutan Umum } \\
\text { e. Metode Analisis Transportasi } \\
\text { f. Sistem Transportasi Cerdas (ITS) } \\
\text { g. Sistem Transportasi Terpadu } \\
\text { h. Teori Pengambilan Keputusan (OR) } \\
\text { i. Rekayasa Sistem Pelayanan Angkutan Barang }\end{array}$ \\
\hline 7 & $\begin{array}{l}\text { Aplikasi matematika rekayasa, } \\
\text { prinsip rekayasa, dan aplikasi } \\
\text { statistik }\end{array}$ & $\begin{array}{l}\text { a. Perencanaan dan Pemodelan Transportasi } \\
\text { b. Perencanaan dan Kebijakan Transportasi } \\
\text { c. Metodologi Penelitian } \\
\text { d. Sistem Transportasi Cerdas (ITS) } \\
\text { e. Manajemen dan Rekayasa Lalu Lintas } \\
\text { f. Infrastruktur Transportasi Berkelanjutan } \\
\text { g. Sistem Transportasi Terpadu } \\
\text { h. Teori Pengambilan Keputusan (OR) }\end{array}$ \\
\hline 8 & $\begin{array}{l}\text { Konsep teoritis dan teknik } \\
\text { perencanaan dan pemodelan } \\
\text { transportasi berbasis permintaan } \\
\text { (transport demand modelling) }\end{array}$ & $\begin{array}{l}\text { a. Perencanaan dan Pemodelan Transportasi } \\
\text { b. Perencanaan dan Kebijakan Transportasi } \\
\text { c. Transportasi dan Tata Guna Lahan } \\
\text { d. Ekonomi Transportasi } \\
\text { e. Sistem Angkutan Umum } \\
\text { f. Lalu Lintas dan Pergerakan } \\
\text { g. Sistem Transportasi Cerdas (ITS) } \\
\text { h. Manajemen dan Rekayasa Lalu Lintas } \\
\text { i. Sistem Transportasi Terpadu } \\
\text { j. Teori Pengambilan Keputusan (OR) } \\
\text { k. Rekayasa Sistem Pelayanan Angkutan Barang }\end{array}$ \\
\hline 9 & $\begin{array}{l}\text { Konsep wawasan tentang teknologi } \\
\text { terkini dan termaju di bidang } \\
\text { transportasi jalan }\end{array}$ & $\begin{array}{l}\text { a. Perencanaan dan Kebijakan Transportasi } \\
\text { b. Sistem Angkutan Umum } \\
\text { c. Manajemen Prasarana Transportasi }\end{array}$ \\
\hline
\end{tabular}




\begin{tabular}{|l|l|l|}
\hline No & \multicolumn{1}{|c|}{ Bahan Kajian } & \multicolumn{1}{c|}{ Mata Kuliah } \\
\hline \multirow{1}{*}{} & & d. Metodologi Penelitian \\
& e. Sistem Transportasi Cerdas \\
& f. Manajemen dan Rekayasa Lalu lintas \\
& g. Infrastruktur Transportasi Berkelanjutan \\
& h. Keselamatan Lalu Lintas \\
& i. Sistem Transportasi Terpadu \\
& j. Teori Pengambilan Keputusan (OR) \\
& k. Rekayasa Sistem Pelayanan Angkutan Barang \\
& 1. Kebijakan Publik \\
\hline
\end{tabular}

\section{STRUKTUR KURIKULUM}

Berdasarkan Standar Nasional Pendidikan Tinggi, Beban studi pada kurikulum program Magister terapan adalah 36-50 sks termasuk tesis, setelah program Diploma IV ; dimana kemampuan wajib program studi 9 sks, kemampuan wajib minat 6-12 sks, kemampuan wajib pilihan 13-21 sks dan kegiatan mandiri berupa penyusunan tesis sebesar: 8 sks termasuk beban seminar dan penulisan artikel jurnal

1. Jumlah maksimal sks yang dapat diikuti oleh mahasiswa per semester adalah 16 (enam belas) sks.

2. Keseluruhan beban studi kurikulum program master dijadwalkan dalam 4 (empat) semester dan dalam pelaksanaannya dapat ditempuh dalam waktu sekurang-kurangnya 3 (tiga) semester dan selama-lamanya 10 (sepuluh) semester.

Kesimpulan

Berdasarkan hasil penelitian disimpulkan beberapa hal sebagai berikut:

1. Menganalisis Profil Lulusan D. IV Transportasi Darat saat ini meliputi Perencana Transportasi, Perekayasa Sistem Transportasi Darat, Perekayaasa Angkutan Umum, Perencana Sistem SImpul dan Integrasi Antar Moda Berdasarkan kebutuhan pemenuhan tugas pokok dan fungsi, maka dibutuhkan komptenesi lanjutan melalui pendidikan program magister 
transportasi, untuk dpat meningkatkan kinerja dari lulusan D. IV Transportasi Darat

2. Berdasarkan Pemetaan, maka Capaian Pembelajaran yang sesuai dengankebutuhan kerja adalah pendidikan Magister Terapan Transportasi, yaitu pada jalur Pendidikan Vokasi, dengan profil sebagai Ahli Pemodelan TransportasiAhli Rekayasa Lalu Lintas, Ahli Integrasi Inter dan Antar Moda, Ahli Sistem Operasional Angkutan Umum.

3. Berdasarkan Profil tersebut diperoleh Capaian Pembelajaran Program Magiister yang mmiliki kriteria sikap, pengetahuan, keterampilan umum dan ketrampilan khusus yang mendukung kualitas kerja setelah lulus.

SARAN

1. Mengingat mendesaknya kebutuhan penyenelnggaraan program studi, maka untuk melengkapi bahasan, maka diperlukan penelitian lanjutan yang mendukung argument kelayakan Sekolah Tinggi Transportasi Darat dalam membentuk program studi Magister Terapan Transportasi

2. Studi Kelayakan tersebut merupakan bagian penting untuk mewujudkan rencana startegis pengembangan Sekolah Tinggi Transportasi Darat. 


\section{Daftar Pustaka}

2012. Undang-Undang Republik Indonesia Nomor 12 Tahun 2012

Tentang Pendidikan Tinggi

2012. Peraturan Presiden Republik Indonesia Nomor 8 Tahun 2012

Tentang Kerangka Kualifikasi Nasional Indonesia

2013. Peraturan Menteri Pendidikan dan Kebudayaan No. 73 Tahun 2013

tentang Penerapan Kerangka Kualifikasi Nasional Indonesia Bidang

Pendidikan Tinggi.

2014. Peraturan Menteri Pendidikan dan Kebudayaan No. 81 Tahun 2014

tentang Ijazah, Sertifikat Kompetensi, dan Sertifikat Profesi.

2015. Peraturan Menteri Riset, Teknologi, dan Pendidikan Tinggi No. 13

Tahun 2015 tentang Rencana Strategis Kemenristekdikti tahun 2015-

2019.

2015. Peraturan Menteri Riset, Teknologi, dan Pendidikan Tinggi No. 44 tahun 2015 tentang Standar Nasional Pendidikan Tinggi

2016. Peraturan Menteri Riset, Teknologi dan Pendidikan Tinggi nomor

32 Tahun 2016 tentang Akreditasi Program Studi dan Perguruan Tinggi.

2016. Peraturan Menteri Riset, Teknologi dan Pendidikan Tinggi No. 62

Tahun 2016 tentang Sistem Penjaminan Mutu Pendidikan Tinggi. 